\title{
Embracing the Skin we are in, Getting Comfortable in our Skin
}

\section{Ogo Chinenye Maduewesi ${ }^{*}$}

Vitiligo Support and Awareness Foundation, Surulere, lagos, Nigeria

Over the years the reactions and adjustments of individuals living with Vitiligo has really evolved. Comparing 5years ago and today, I can categorically say there is huge positive difference on individual's selfacceptance and in embracing self as we are.

As a Vitiligo patient-advocate who's been working on the Vitiligo cause for over 7years, I want to review the self-acceptance and confidence of the man living with Vitiligo as at 2014 with regards to feedback from Social media. Sharing pictures with stories and experiences on different platforms on Social media particularly facebook has really encouraged, inspired, built confidence immensely and above all improved tremendously Quality of Life's QoL of individuals living with Vitiligo more than ever since I have been working tirelessly on the Vitiligo cause.

Image is everything in our world today, people are reading less, but responding much more to images. Practical confirmation of the above statement is the positive effects of feedbacks from Wold Vitiligo Day June 25 facebook page. We encouraged and kept encouraging patients to share their pictures to help themselves and encourage someone too, to my greatest amazement, we saw an entirely different response June 2014, the song suddenly changed to 'comfortable in the skin I am in' self-love \& self-acceptance', 'No cure, don't care' etc...... it was really amazing and so encouraging to see Vitiligo patients accepting themselves for who they are, majority are now living have been just existing for some long years.

Few feedbacks out of many on World Vitiligo Day - June $\mathbf{2 5}^{\text {th }}$ facebook page https://www.facebook.com/WorldVitiligoDay

This page has helped me deal with my vitiligo. To embrace it better and not cover it up all the time. I have had it for 28 yrs now and it is still not as bad as these other brave vitiligo persons on this page. It does not show up as strong on my skin as these other vitiligo people. Bless all of you who have it and your courage to face it every day.

Mary W. Jolly

It came about extremely fast; and it was very difficult for me, being a doctor, to understand why was this happening to me? from a couple of weeks ago. I found that learning to accept my disease resulted in a vast improvement, and most of the spots have disappeared. I still have a few, but they merely serve as a reminder that we are not perfect; and all that matters is what is in our hearts.Maria Angeles from Cuba.

My great observation and a simple truth is that self-acceptance leads to world/public acceptance. Humans simply accept and treat one how he/she presents self.

\author{
Thank you \\ Ogo Maduewesi \\ Founder/Executive Director \\ Vitiligo Support and Awareness Foundation \\ vitsupng@gmail.com \\ www.vitsaf.org
}

*Corresponding author: Ogo Chinenye Maduewesi, Executive director, Vitiligo Support and Awareness Foundation, 51 Oyekan Road, Off Akerele Street, Surulere, Lagos 23401, Nigeria, Tel: +2348063638030; E-mail: vitsupng@gmail.com

Received August 01, 2014; Accepted September 06, 2014; Published September 08, 2014

Citation: Maduewesi OC (2014) Embracing the Skin we are in, Getting Comfortable in our Skin. Pigmentary Disorders 1:129. doi:10.4172/JPD.1000129

Copyright: ๑ 2014 Maduewesi OC. This is an open-access article distributed under the terms of the Creative Commons Attribution License, which permits unrestricted use, distribution, and reproduction in any medium, provided the original author and source are credited. 